\title{
Intermediate-term oncologic outcomes after video-assisted thoracoscopic thymectomy for early-stage thymoma
}

\author{
Yasushi Sakamaki, MD, ${ }^{\mathrm{a}}$ Tomofumi Oda, MD, ${ }^{\mathrm{a}}$ Go Kanazawa, MD, ${ }^{\mathrm{a}}$ Toshio Shimokawa, PhD, ${ }^{\mathrm{b}}$ \\ Tetsuo Kido, MD, ${ }^{\mathrm{c}}$ and Hiroyuki Shiono, $\mathrm{MD}^{\mathrm{d}}$
}

\begin{abstract}
Objective: To evaluate the impact on patient survival of video-assisted thoracoscopic surgery (VATS) thymectomy for the treatment of early-stage thymoma, by comparing the intermediate-term oncologic outcomes with outcomes after open thymectomy.
\end{abstract}

\begin{abstract}
Methods: Eighty-two patients who underwent complete resection of a Masaoka stage I or II thymoma between November 1998 and December 2011 were reviewed.

Results: The patients included 32 men and 50 women (median age, 57 years; range, 20-90 years), of whom 44 had stage I thymoma and 38 had stage II thymoma. Seventy-one patients underwent VATS, of whom 4 (5.6\%) underwent conversion to open thymectomy; the remaining 11 patients underwent planned open thymectomy. Thirty-six patients underwent total thymectomy and 46 underwent partial thymectomy. Operative mortality was nil. The tumor stage, tumor size, and proportion of patients who underwent total thymectomy were not significantly different between the open and VATS thymectomy groups. The median follow-up period was 49 months (VATS, 48 months; open, 52 months). There was a significant difference between the 2 groups for the estimated 5-year overall survival (VATS, $97.0 \%$; open, $79.5 \% ; P=.041$ ) but not in the estimated 5-year recurrence-free survival.
\end{abstract}

Conclusions: Our findings indicate that the intermediate-term oncologic outcomes after VATS thymectomy for early-stage thymoma are as favorable as outcomes after open thymectomy. Further follow-up is still required to evaluate the long-term outcomes after VATS thymectomy. (J Thorac Cardiovasc Surg 2014;148:1230-7)

Supplemental material is available online.

Complete resection is the most important aspect of treatment to prolong survival in patients with any stage of thymoma. ${ }^{1-4}$ In stage I or II (early-stage) thymoma, thymectomy usually achieves complete resection of the tumor, resulting in favorable oncologic outcomes. ${ }^{1-5}$ Independently of the favorable outcomes after open thymectomy, advances in both equipment and expertise for video-assisted thoracoscopic surgery (VATS) have expanded the use of VATS thymectomy for the treatment of early-stage thymoma over the past 2 decades. $^{6-10}$

\footnotetext{
From the Department of Chest Surgery, ${ }^{a}$ Osaka Police Hospital, Osaka, Japan; Department of Regional Social Management, ${ }^{\mathrm{b}}$ The Faculty of Life and Environmental Sciences, University of Yamanashi, Kofu, Japan; Department of Surgery, ${ }^{c}$ Shion Clinic, Osaka, Japan; Department of Thoracic Surgery, ${ }^{\mathrm{d}}$ Kinki University Nara Hospital, Ikoma, Japan.

Disclosures: Authors have nothing to disclose with regard to commercial support.

Received for publication July 24, 2013; revisions received Dec 14, 2013; accepted for publication Jan 21, 2014; available ahead of print Feb 19, 2014.

Address for reprints: Yasushi Sakamaki, MD, Department of Chest Surgery, Osaka Police Hospital, Kitayamacho 10-31, Tennoji, Osaka 543-8502, Japan (E-mail: sak@serenade.plala.or.jp).

0022-5223/\$36.00

Copyright (c) 2014 by The American Association for Thoracic Surgery

http://dx.doi.org/10.1016/j.jtcvs.2014.01.029
}

However, few data have been published regarding the long-term oncologic outcomes (10 years or longer) of VATS thymectomy compared with open thymectomy. Although many reports have suggested that VATS thymectomy for early-stage thymoma is technically feasible and safe, long-term follow-up data are not yet available. ${ }^{7-10}$

The appropriate extent of thymectomy for complete resection of thymoma also remains unclear. Many investigators recommend complete resection of the thymoma with complete resection of the thymus, even in patients without myasthenia gravis (MG) and without evidence of involvement of the rest of the thymus. ${ }^{1,11}$ However, it is not clear whether total thymectomy (TTx) results in a better prognosis than tumor resection alone (thymomectomy). 2,3,8,9 Nakagawa and colleagues $^{3}$ studied a series of 126 patients, and found no difference in survival between patients who underwent TTx and those who underwent thymomectomy. Although some studies have reported on short-term outcomes after VATS partial thymectomy (PTx) for early-stage thymoma without MG, the longterm oncologic outcomes of this procedure remain unclear. $^{8,9}$

This article presents our single-center experience of the surgical treatment of early-stage thymoma over a 13-year period. VATS was the most common surgical approach, and VATS PTx was performed more frequently than VATS TTx. The aim of this study was to evaluate the impact 


$$
\begin{aligned}
& \text { Abbreviations and Acronyms } \\
& \begin{array}{ll}
\text { CT } & =\text { computed tomography } \\
\text { MG } & =\text { myasthenia gravis } \\
\text { MRI } & \text { magnetic resonance imaging } \\
\text { OS } & =\text { overall survival } \\
\text { PTMG } & =\text { postthymectomy myasthenia gravis } \\
\text { PTx } & =\text { partial thymectomy } \\
\text { RFS } & \text { relapse-free survival } \\
\text { TTx } & =\text { total thymectomy } \\
\text { VATS } & =\text { video-assisted thoracoscopic surgery }
\end{array}
\end{aligned}
$$

on patient survival of VATS thymectomy for the treatment of early-stage thymoma by analyzing intermediate-term oncologic outcomes. Outcomes after PTx in patients with thymoma who did not have clinical signs or laboratory evidence of MG were also evaluated.

\section{MATERIALS AND METHODS}

Our experience of the surgical treatment of stage I and II thymoma at the Department of Chest Surgery, Osaka Police Hospital, between November 1998 and December 2011 is reviewed. The study was approved by the institutional review board of Osaka Police Hospital. The preoperative diagnosis of noninvasive thymoma was based on computed tomography (CT) and/or magnetic resonance imaging (MRI) findings, without biopsy, according to the criteria previously described. ${ }^{12,13}$ The final diagnosis of thymoma was based on histologic examination findings during and after surgery. Frozen section examination of the resected specimen was performed during surgery in all cases to ensure clear surgical margins. The Masaoka staging system ${ }^{14}$ was used to define stage I and II thymoma. The World Health Organization classification system ${ }^{15,16}$ was used to classify tumors according to histologic subtype $\mathrm{A}, \mathrm{AB}, \mathrm{B} 1, \mathrm{~B} 2$, or B3. Patients with advanced-stage disease or with type $C$ or carcinoid tumors were treated differently and were excluded from this study.

\section{Patient Characteristics}

Among the 105 patients who underwent complete resection of a thymic epithelial tumor during the study period, 82 had stage I or II thymoma. The process of patient selection is shown in Figure E1. All patients had a single mass in the thymus on imaging examinations, with no evidence of multifocal tumor. These 82 patients included 32 men and 50 women (mean age, 57 years; range, 20-90 years), of whom 44 had stage I thymoma and 38 had stage II thymoma. Thirty-six patients underwent TTx and 46 underwent PTx. VATS thymectomy was planned in 71 patients and open thymectomy in 11 patients. Of the 71 VATS procedures, 67 were completed as planned, and 4 were converted to open resection. Twenty-nine patients (35\%) had coexisting MG. The patient characteristics are shown in Table 1 .

\section{Surgical Approaches and Procedures}

The criteria for selecting the surgical approach were as follows. VATS thymectomy was planned if the tumor characteristics on CT and/or MRI were noninvasive, and open thymectomy was planned if tumor invasion of the great vessels or the pericardium was suspected or could not be excluded. VATS thymectomy was converted to open thymectomy via median sternotomy if there were severe adhesions that were difficult to distinguish from vascular or pericardial invasion, or if there was bleeding from a major vessel that could not be controlled by compression. TTx was performed according to the extended thymectomy criteria described by
Masaoka and colleagues, ${ }^{17}$ and involved en bloc resection of the thymus with the perithymic adipose tissues between the phrenic nerves and from the diaphragm to the thyrothymic lamina. PTx was usually subtotal thymectomy, but included a variety of procedures ranging from hemi- to sub$\operatorname{total}^{8}$ thymectomy, depending on the size and location of the tumor. The decision to perform TTx was based on the presence of MG, regardless of the surgical approach.

\section{Details of Video-Assisted Thoracoscopic Thymectomy}

During unilateral or bilateral VATS thymectomy, the thymus including the thymoma was resected as previously described. ${ }^{8,18}$ Briefly, the patient was placed in the supine position under general anesthesia, and the trachea was intubated with a double-lumen tube. Three ports were placed between the anterior and midaxillary lines on the side of operation. For the bilateral approach, these ports were placed on each side when entering the respective hemithorax. The perithymic tissues and thymoma were bluntly dissected and excised, using a $30^{\circ}$ angled 5-mm-diameter telescope and surgical instruments. The thymic veins were meticulously dissected and divided using an ultrasonically activated device or a bipolar vesselsealing system. For TTx, a cervical incision or chest wall lifting method ${ }^{18}$ was not always required. After resection, 1 of the ports was enlarged to allow extraction of the specimen in a plastic bag. In some patients with a bulky tumor, the specimen was extracted through a subxiphoid incision. TTx was performed via a subxiphoid approach with a sternum-lifting method (Laparolift and Laparofan system; Origin Medsystems, Menlo Park, Calif) as previously described ${ }^{19}$ from 1998 to 2007 , and via a transthoracic approach from 2008 to 2011.

\section{Collection of Data}

Data on patient demographics, tumor characteristics, tumor stage, presence of MG, extent of thymectomy, surgical approach, duration of operation, surgical complications, and adjuvant therapy were collected. The Osserman score and Myasthenia Gravis Foundation of America grade were recorded in patients with MG before and after surgery. CT was performed every 6 months after surgery for the first year and yearly thereafter, to screen for signs of disease recurrence.

\section{Statistical Analysis}

The primary end point was overall survival (OS) and the secondary end point was relapse-free survival (RFS). Statistical analyses were performed according to the intention-to-treat principle. The actuarial OS and RFS curves were calculated using the Kaplan-Meier method, and differences between survival curves were analyzed using the log-rank test. Patients were censored for OS at the time of the last follow-up. RFS was defined as the time from thymectomy to the detection of relapse. Patients who died of non-thymoma-related causes with no evidence of relapse were censored at the time of death. Patient characteristics were compared between the open and VATS thymectomy groups and between the TTx and PTx groups using the $\chi^{2}$ test for categorical variables and the Student $t$ test for continuous variables. The mean values were compared between subgroups using one-way analysis of variance. The Cox proportional hazards model was used for multivariate analyses of prognostic factors.

\section{RESULTS}

\section{Tumor Characteristics in Patients Who Underwent Open Versus Thoracoscopic Thymectomy}

There were no significant differences between the open and VATS thymectomy groups in terms of age, male/female ratio, proportions who underwent TTx and adjuvant radiotherapy, or proportion with improvement of MG after 
TABLE 1. Comparisons of variables between patients who underwent open and VATS thymectomy

\begin{tabular}{|c|c|c|c|c|}
\hline Variable & $\begin{array}{c}\text { Entire } \\
(\mathbf{n}=\mathbf{8 2})\end{array}$ & $\begin{array}{c}\text { Open } \\
(\mathbf{n}=11)\end{array}$ & $\begin{array}{c}\text { VATS } \\
(\mathbf{n}=\mathbf{7 1})^{*}\end{array}$ & $P$ value \\
\hline Sex & & & & .89 \\
\hline Male & $32(39)$ & $5(45)$ & $27(38)$ & \\
\hline Female & $50(61)$ & $6(55)$ & $44(62)$ & \\
\hline Age (y) & & & & .48 \\
\hline Median & 57 & 62 & 57 & \\
\hline Range & $20-90$ & $27-86$ & $20-90$ & \\
\hline Tumor stage & & & & .36 \\
\hline Stage I & $44(54)$ & $4(36)$ & $40(56)$ & \\
\hline Stage II & $38(46)$ & $7(64)$ & $31(44)$ & \\
\hline WHO histologic type $\dagger$ & & & & .84 \\
\hline B2-B3 & $20(25)$ & $3(33)$ & $17(24)$ & \\
\hline Other $\ddagger$ & $60(75)$ & $6(67)$ & $54(76)$ & \\
\hline Tumor size $(\mathrm{cm})$ & & & & .10 \\
\hline Median & 3.9 & 5.5 & 3.5 & \\
\hline Range & $1.0-15$ & $2.3-15$ & $1.0-11$ & \\
\hline Extent of thymectomy & & & & .28 \\
\hline Total & $36(44)$ & $7(64)$ & $29(41)$ & \\
\hline Partial & $46(56)$ & $4(36)$ & $42(59)$ & \\
\hline Combined resection & $11(13)$ & $5(45)$ & $6(8.4)$ & $<.01$ \\
\hline Adjuvant radiotherapy & $8(10)$ & $1(9)$ & $7(9.8)$ & .64 \\
\hline Presence of MG & $29(35)$ & $3(27)$ & $26(37)$ & .79 \\
\hline Follow-up (mo) & & & & .50 \\
\hline Median & 49 & 52 & 48 & \\
\hline Range & $2-154$ & $2-122$ & $2-154$ & \\
\hline
\end{tabular}

Values are the number $(\%)$ of patients unless otherwise indicated. VATS, Videoassisted thoracoscopic surgery; $W H O$, World Health Organization; $M G$, myasthenia gravis. *Including 4 cases that were converted to open surgery. $\dagger$ Not determined in 2 of 82 cases. $\ddagger$ Types $\mathrm{A}, \mathrm{AB}$, and $\mathrm{B} 1$.

surgery. Patients who underwent VATS thymectomy tended to have a smaller thymoma and a higher likelihood of stage I thymoma, but these differences between the 2 groups were not significant. The frequency of combined resection of the adjacent structures (pericardium, left innominate vein, phrenic nerve, and peripheral lung tissue) was significantly higher in the open thymectomy group than in the VATS thymectomy group $(P<.01)$. Combined resection was performed in patients with severe adhesions that were difficult to distinguish from tumor invasion. The open and VATS thymectomy groups were each divided into 2 subgroups according to histologic subtype: types $\mathrm{A}, \mathrm{AB}$, and $\mathrm{B} 1$; and types B2 and B3. There was no difference in the proportion of patients with a high-risk histologic subtype (B2 or B3) between the open and VATS thymectomy groups. Comparisons of patient characteristics between the open and VATS thymectomy groups are shown in Table 1.

\section{Tumor Characteristics in Patients Who Underwent Total Versus Partial Thymectomy}

There were no significant differences between the TTx and PTx groups in terms of tumor size, ratio of stage I versus stage II tumors, or the proportions of patients who
TABLE 2. Short-term surgical outcomes after thymectomy

\begin{tabular}{|c|c|c|c|c|}
\hline \multirow[b]{2}{*}{ Procedure } & \multicolumn{2}{|c|}{ Open thymectomy } & \multicolumn{2}{|c|}{ VATS thymectomy } \\
\hline & $\begin{array}{c}\text { Total } \\
(\mathrm{n}=7)\end{array}$ & $\begin{array}{l}\text { Partial } \\
(n=4)\end{array}$ & $\begin{array}{c}\text { Total } \\
(\mathbf{n}=\mathbf{2 9}) \\
\end{array}$ & $\begin{array}{c}\text { Partial } \\
(n=42) \\
\end{array}$ \\
\hline \multicolumn{5}{|l|}{ Surgical approach } \\
\hline \multicolumn{5}{|l|}{ Open } \\
\hline Sternotomy & 7 & 3 & $2 *$ & $2^{*}$ \\
\hline Thoracotomy & & 1 & & \\
\hline \multicolumn{5}{|l|}{ VATS } \\
\hline Subxiphoid & & & $17(59)$ & \\
\hline Unilateral & & & & 42 \\
\hline Bilateral & & & $12(41)$ & \\
\hline \multicolumn{5}{|l|}{ Tumor size $(\mathrm{cm})$} \\
\hline Mean \pm SD & $5.0 \pm 2.1$ & $8.2 \pm 5.9 \dagger$ & $3.3 \pm 1.5$ & $4.3 \pm 2.2$ \\
\hline Range & $2.5-7.0$ & $4.7-15$ & $1.0-6.0$ & $1.3-11$ \\
\hline \multicolumn{5}{|l|}{ Tumor stage } \\
\hline Stage I & $1(14)$ & $2(50)$ & $17(59)$ & $23(55)$ \\
\hline Stage II & $6(86)$ & $2(50)$ & $12(41)$ & $19(45)$ \\
\hline Combined resection & $3(43)$ & $2(50)$ & $1(3)$ & $5(12)$ \\
\hline \multicolumn{5}{|l|}{ Resected structures } \\
\hline & P: 1 & P: 1 & L: 1 & $\mathrm{P}: 1^{*}$ \\
\hline & L: 1 & $\mathrm{I}+\mathrm{L}: 1$ & & L: 3 \\
\hline & $\mathrm{P}+\mathrm{L}+\mathrm{Ph}: 1$ & & & $\mathrm{I}+\mathrm{P}: 1^{*}$ \\
\hline \multicolumn{5}{|l|}{ Operating time (min) } \\
\hline Mean \pm SD & $191 \pm 29$ & $176 \pm 96$ & $208 \pm 58$ & $136 \pm 65$ \\
\hline Range & $160-245$ & $55-290$ & $105-326$ & $46-355$ \\
\hline Cases with MG & $3(43)$ & 0 & $26(90)$ & 0 \\
\hline Palliation of MG & $2(67)$ & & $19(73)$ & \\
\hline Postthymectomy MG & 0 & 0 & 0 & $2(5)$ \\
\hline
\end{tabular}

Values are the number (\%) of patients unless otherwise indicated. VATS, Videoassisted thoracoscopic surgery; $S D$, standard deviation; $P$, pericardium; $L$, peripheral lung tissue; $I$, left innominate vein; $P h$, phrenic nerve; $M G$, myasthenia gravis. $*$ Cases that were converted to open surgery. $\dagger P<.05$ versus open total thymectomy and $<.01$ versus VATS total and partial thymectomy. $\ddagger P<.01$ versus VATS total thymectomy and $<.05$ versus open total thymectomy.

underwent VATS, adjuvant radiotherapy, or combined resection of adjacent structures. The PTx group tended to have a shorter follow-up period than the TTx group, but this difference was not significant. The proportions of women and patients with B2 or B3 thymoma were significantly higher in the TTx group than in the PTx group (both $P<.01$ ), and patients in the TTx group were significantly younger. Comparisons of characteristics between patients who underwent TTx and PTx are shown in Table E1.

\section{Short-Term Surgical Outcomes}

There were no significant differences in operating time between patients who underwent open TTx and those who underwent VATS TTx, or between those who underwent open PTx and those who underwent VATS PTx. There was a significant difference in operating time between TTx and PTx in the VATS group $(P<.01)$, but not in the open group. The tumor size was significantly larger in the open PTx subgroup than in the open TTx subgroup $(P<.05)$ and both subgroups of VATS thymectomy 

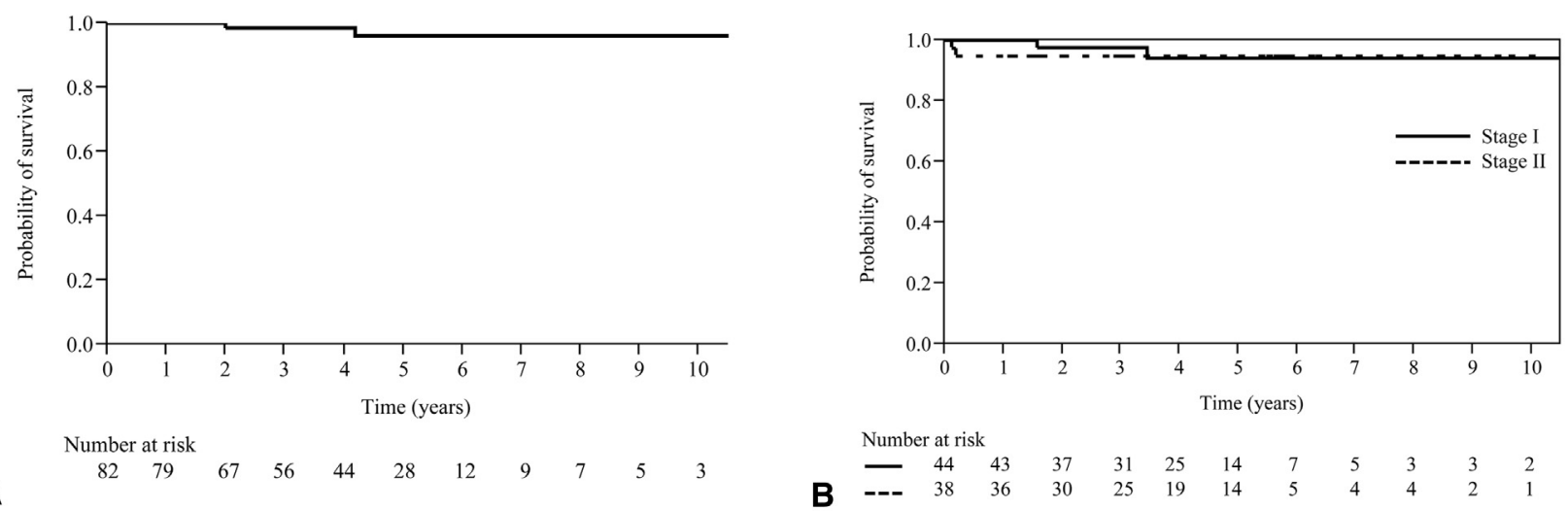

A
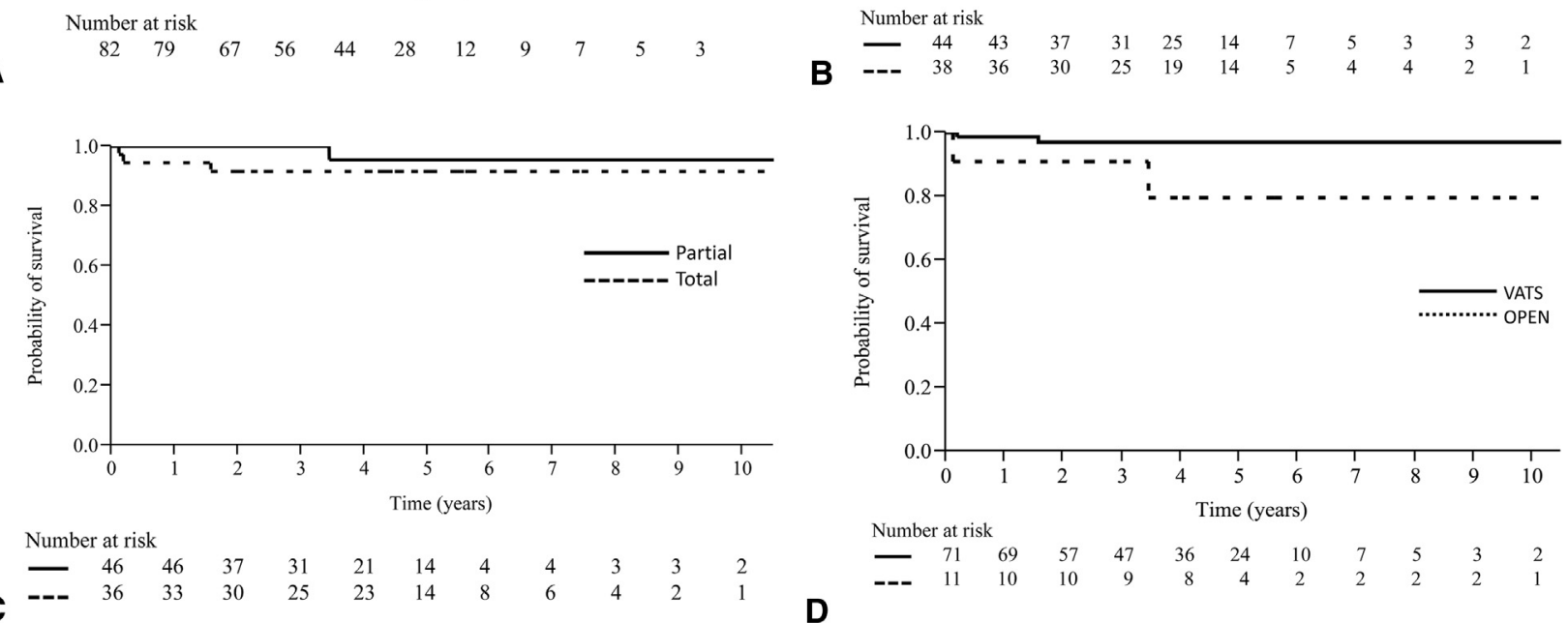

D
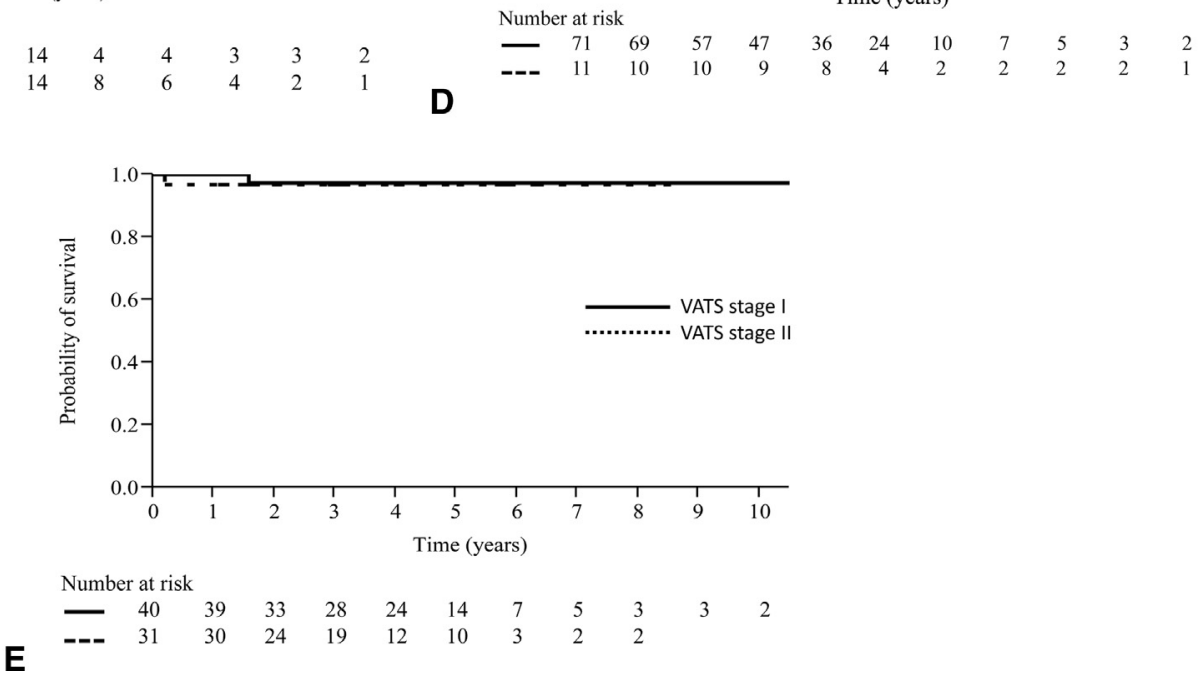

FIGURE 1. Kaplan-Meier curves illustrating overall survival: A, entire cohort; B, stratified by tumor stage (stage I vs stage II); C, stratified by extent of thymectomy (total vs partial); D, stratified by surgical approach (open vs thoracoscopic); E, stratified by tumor stage in patients who underwent videoassisted thoracoscopic thymectomy (stage I vs stage II). VATS, Video-assisted thoracoscopic surgery.

(both $P<.01$ ). There were no significant correlations between tumor size and operating time in the TTx, PTx, open, or VATS thymectomy groups. There was no significant difference in operating time between right-sided and left-sided VATS PTx (data not shown). Conversion from VATS to open resection occurred in 4 of 71 cases $(5.6 \%)$, because of severe adhesions between the tumor and the left innominate vein in 2 cases $(2.8 \%)$, and because of uncontrollable bleeding in the other 2 cases. Symptoms of MG were palliated after thymectomy in 2 of the 3 patients
$(67 \%)$ in the open group and in 19 of the 26 patients $(73 \%)$ in the VATS group. Postthymectomy myasthenia gravis (PTMG) occurred in 2 of the 53 patients $(3.8 \%)$, or $5 \%$ of those who underwent VATS PTx: at 5 months after PTx in 1 patient aged 36 years and at 21 months after PTx in 1 patient aged 77 years. In the second patient, serum antiacetylcholine receptor antibody was confirmed to be negative before thymectomy. The first patient underwent repeat VATS to remove the remnant thymus, and achieved complete remission of generalized MG postoperatively. 
TABLE 3. Cox proportional hazards analysis of variables affecting prognosis

\begin{tabular}{|c|c|c|c|c|}
\hline \multirow[b]{2}{*}{ Risk factor } & \multicolumn{2}{|r|}{ Overall survival } & \multicolumn{2}{|c|}{ Relapse-free survival } \\
\hline & $\begin{array}{c}P \\
\text { value }\end{array}$ & HR $(95 \%$ CI $)$ & $\begin{array}{c}P \\
\text { value }\end{array}$ & HR $(95 \%$ CI $)$ \\
\hline Age & .826 & $0.998(0.982-1.015)$ & .617 & $0.996(0.979-1.012)$ \\
\hline Tumor stage & .346 & $1.286(0.762-2.168)$ & .298 & $1.327(0.779-2.263)$ \\
\hline $\begin{array}{c}\text { WHO B2-B3 } \\
\text { histology }\end{array}$ & .606 & $0.852(0.464-1.566)$ & .716 & $0.892(0.481-1.655)$ \\
\hline $\begin{array}{l}\text { Postoperative } \\
\text { RT }\end{array}$ & .167 & $0.479(0.166-1.362)$ & .147 & $0.458(0.159-1.317)$ \\
\hline $\begin{array}{l}\text { Myasthenia } \\
\text { gravis }\end{array}$ & .083 & $2.192(0.902-5.324)$ & .078 & $2.253(0.914-5.552)$ \\
\hline $\begin{array}{l}\text { Extent of } \\
\text { thymectomy* }\end{array}$ & .051 & $0.409(0.166-1.003)$ & .041 & $0.386(0.155-0.960)$ \\
\hline
\end{tabular}

The second patient declined reoperation and was prescribed medication for ocular type MG. The short-term surgical outcomes according to surgical approach and extent of thymectomy are shown in Table 2.

\section{Overall Survival}

The median (range) follow-up period was 49 (2-154) months for the entire cohort, 48 (2-154) months for the VATS thymectomy group, and 52 (2-122) months for the open thymectomy group. Operative mortality was nil, and there were no treatment-related or thymoma-related deaths. Four patients died of non-thymoma-related causes during the follow-up period at 2, 2, 19, and 41 months after surgery, respectively. The 5-year actuarial OS for the entire cohort was $94.1 \%$ (Figure 1, A). The 5-year OS was $94.1 \%$ for patients with stage I thymoma and $94.7 \%$ for those with stage II thymoma $(P=.79)$ (Figure 1, $B)$; 5-year OS was $91.6 \%$ for the TTx group and $95.4 \%$ for the PTx group $(P=.24)$ (Figure 1 , $C)$. The 5-year OS was significantly higher for the VATS thymectomy group than for the open thymectomy group $(97.0 \%$ vs $79.5 \%, P=.041$ ) (Figure $1, D$ ). In the VATS thymectomy group, the 5-year OS was $97.3 \%$ for patients with stage I thymoma and $96.7 \%$ for those with stage II thymoma $(P=.82)$ (Figure 1,E). Multivariate analysis did not identify any independent predictors of OS for stage I or II thymoma (Table 3).

\section{Recurrence-Free Survival}

Two patients developed pleural recurrence during the follow-up period. These patients both underwent TTx for stage II thymoma with MG (1 underwent VATS TTx and 1 underwent VATS TTx converted to open TTx). No other recurrences were identified. The 5-year actuarial RFS for the entire cohort was $90.4 \%$ (Figure 2, A). The 5-year RFS was $94.1 \%$ for patients with stage I thymoma and $85.4 \%$ for those with stage II thymoma $(P=.23)$ (Figure 2, B), $84.3 \%$ for the TTx group and $95.4 \%$ for the PTx group $(P=.07$ ) (Figure 2, $C$ ), and $92.4 \%$ for the VATS thymectomy group and $79.5 \%$ for the open thymectomy group $(P=.19)$ (Figure $2, D)$. In the VATS thymectomy group, the 5-year RFS was $97.3 \%$ for patients with stage I thymoma and $83.3 \%$ for those with stage II thymoma $(P=.13)$ (Figure 2, $E)$. Multivariate analysis identified only the extent of thymectomy as an independent predictor of RFS for both stage I and II thymoma (Table 3).

\section{DISCUSSION \\ Oncologic Outcomes}

Most previous studies of thoracoscopic thymectomy for thymoma have reported short-term surgical outcomes but not oncologic outcomes. ${ }^{5}$ However, several recent studies reported survival and recurrence data for up to 10 years after VATS thymectomy. ${ }^{20-22}$ Pennathur and colleagues ${ }^{20}$ compared 18 patients who underwent VATS thymectomy for stage I or II thymoma with 22 patients who underwent open thymectomy, and found no significant differences in the 5-year OS and RFS between the 2 groups. Chung and colleagues ${ }^{21}$ studied intermediate-term outcomes in 25 patients without MG who underwent VATS thymectomy, and found 5- and 7-year RFS similar to those of open thymectomy. Furthermore, a multicenter European study of the largest series of robot-aided VATS thymectomy studied to date found a low rate of conversion to open surgery and a 5 -year OS similar to open thymectomy. ${ }^{22}$ In this study, we reviewed our 13-year experience of the surgical treatment of stage I and II thymoma, and found similar outcomes to those reported in larger series. ${ }^{20,21}$ The intermediate-term oncologic outcomes were as favorable as the outcomes after open thymectomy, supporting the feasibility of VATS thymectomy for the treatment of noninvasive thymoma. The 5-year OS after VATS thymectomy was slightly higher than after open thymectomy, and the 5-year RFS after VATS thymectomy was as favorable as those after open thymectomy. The OS and RFS after VATS thymectomy were similar to previously reported outcomes. ${ }^{1-5}$

\section{Recurrence of Thymoma}

Two patients developed pleural recurrence, both of whom were scheduled for VATS TTx for MG with B2 thymoma in stage II. One of these patients underwent bilateral transthoracic VATS TTx as planned, and the other underwent initial subxiphoid VATS TTx converted to transsternal open TTx. Both recurrences were unilateral. These findings may be inconsistent with previously reported findings that thymoma tends to have a lower rate of recurrence in patients with MG than in those without $\mathrm{MG}^{23,24}$ but they are consistent with previous findings that patients with $\mathrm{B} 2$ or B3 thymoma have higher relapse rates than those with other histologic subtypes. ${ }^{1-4}$ Manipulation of the tumor may have resulted in tumor cell implantation in these cases, even though the tumor capsule was not grasped or 

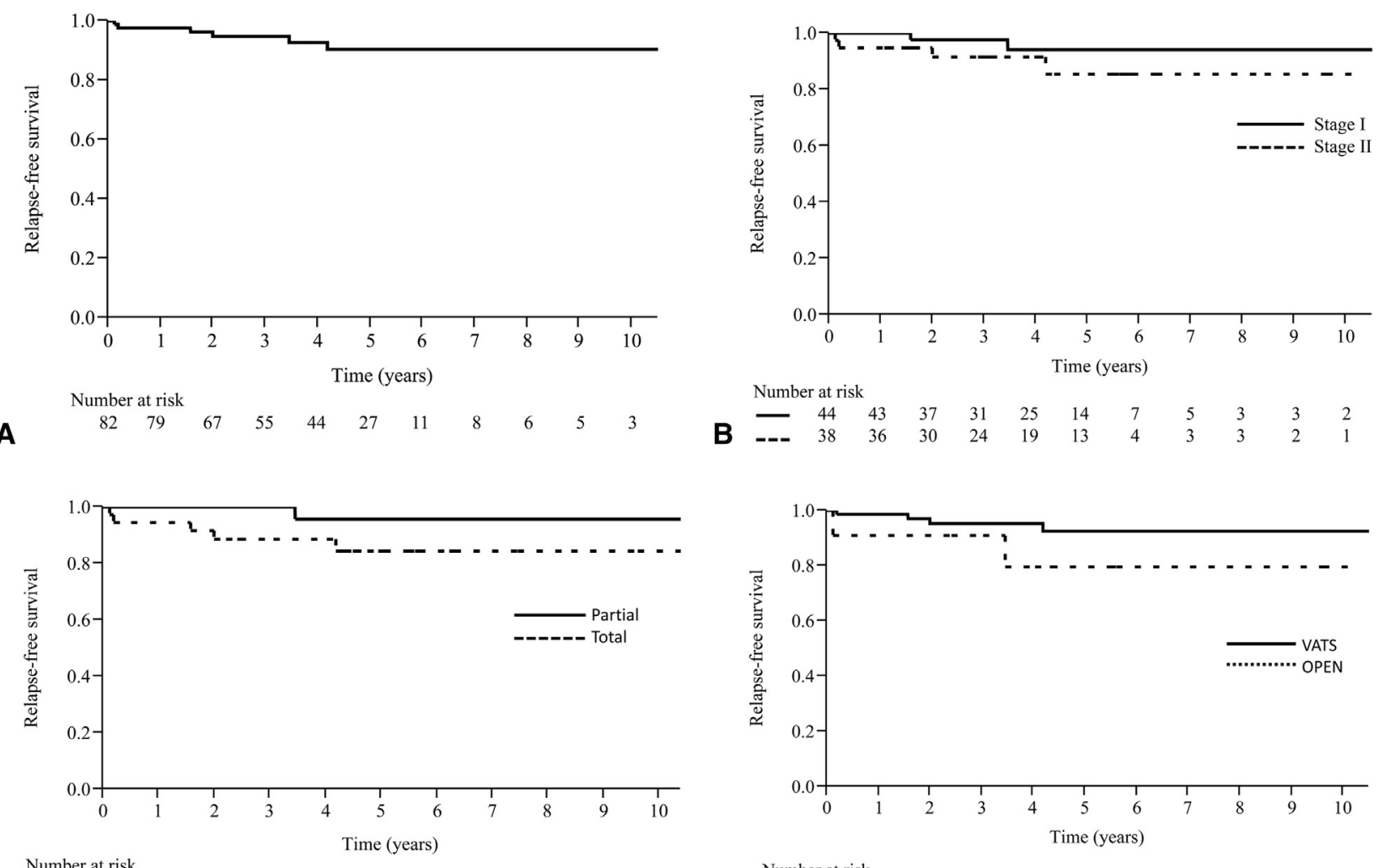

\begin{tabular}{l}
\multicolumn{2}{l}{ Number at risk } \\
\hline $\mathbf{B}$
\end{tabular}
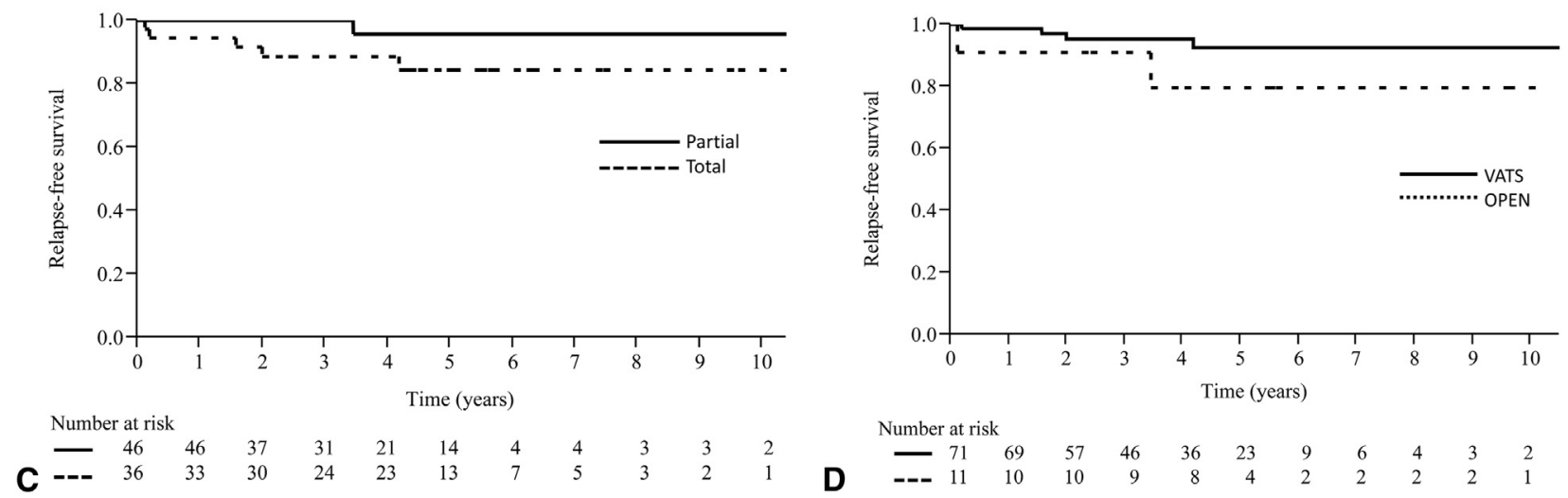

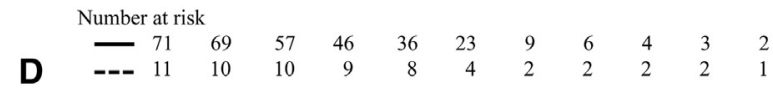

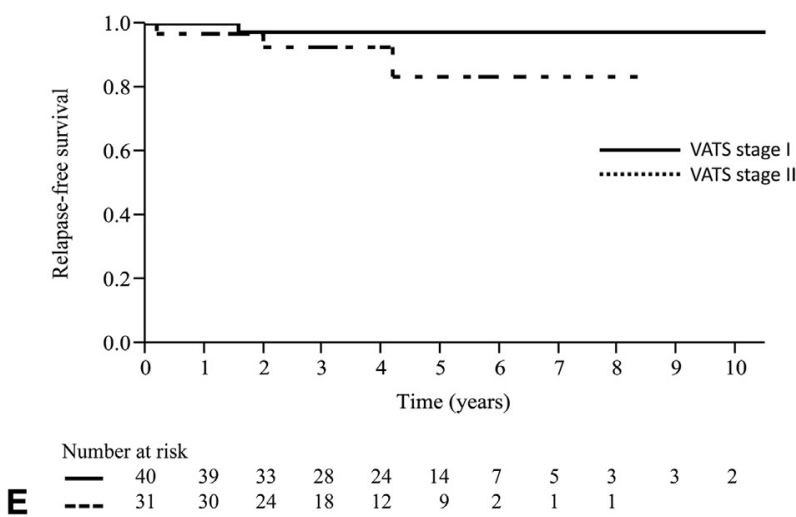

FIGURE 2. Kaplan-Meier curves illustrating relapse-free survival: A, entire cohort; B, stratified by tumor stage (stage I vs stage II); C, stratified by extent of thymectomy (total vs partial); D, stratified by surgical approach (open vs thoracoscopic); E, stratified by tumor stage in patients who underwent videoassisted thoracoscopic thymectomy (stage I vs stage II). VATS, Video-assisted thoracoscopic surgery.

cut during surgery. Lucchi and colleagues ${ }^{25}$ suggested that VATS thymectomy may carry a higher risk of pleural recurrence than open thymectomy because the procedure involves opening of the mediastinal pleura. However, our findings do not indicate that entering the pleural space during VATS thymectomy increases the risk of pleural recurrence compared with transsternal open thymectomy. In the patient who underwent subxiphoid VATS TTx converted to open TTx and developed pleural recurrence, the pleural spaces remained closed throughout the VATS procedure.

\section{Partial Thymectomy}

Marulli and colleagues ${ }^{22}$ recommended subtotal VATS thymectomy for selected patients with thymoma. In this study, we also found that PTx was feasible for the treatment of noninvasive thymoma without MG. There were no cases of marginal or mediastinal recurrence during the follow-up period. Although concern about tumor recurrence in the remaining thymus may limit the use of PTx, our findings suggest that PTx with negative surgical margins does not carry a greater risk of recurrence than TTx. Metachronous second 
primary thymoma is rare, and therefore does not significantly influence the treatment of thymoma patients in general. ${ }^{26,27}$ PTMG occurred in 2 patients in this series who had undergone PTx. Some authorities recommend TTx in all patients with thymoma because of the possibility of PTMG. ${ }^{1}$ However, it is difficult to predict which patients will develop PTMG, and PTMG may occur even after extended thymectomy. ${ }^{28,29}$ We previously encountered a case of PTMG that occurred 9 years after transsternal TTx for stage III thymoma, and therefore consider that PTMG is not completely preventable by performing TTx.

\section{Indications for VATS Thymectomy}

Factors such as tumor size and invasion should be considered when determining the indications for VATS thymectomy. Thoracoscopic resection of bulky or invasive thymoma remains technically challenging and controversial. ${ }^{10,30}$ There is currently no consensus regarding the tumor size limit for VATS thymectomy. Most investigators agree that VATS thymectomy is technically feasible for thymoma measuring up to $5 \mathrm{~cm}$ in diameter. ${ }^{10,22}$ Our criteria for selecting VATS thymectomy were more dependent on freedom from invasion into the great veins and the pericardium than on tumor size alone. The factors indicating invasion on imaging examinations have been widely studied, ${ }^{12,13}$ and should be considered when selecting the surgical approach.

\section{Therapeutic Protocol}

Our therapeutic protocols varied in several ways during the study period. First, PTx replaced TTx as the procedure of choice in the absence of MG partway through the series. Before this change, we performed TTx in all patients. Second, the access for TTx was subxiphoid in some cases and via a bilateral transthoracic approach in other cases, based on the experience and preference of the surgeon. Although the technical feasibility and advantages of both approaches have been described in several reports, ${ }^{8-10,18,19,31,32}$ it is difficult to determine whether one approach is better overall than the other. Third, in 2006 we stopped using adjuvant radiotherapy in patients with B2 or B3 thymoma in stage II. Some reports suggest that adjuvant radiotherapy reduces the risk of mediastinal recurrence, but not pleural recurrence. $^{33,34}$ More recently, Utsumi and colleagues ${ }^{35}$ reported that complete resection alone was sufficient for prolonging survival in patients with early-stage thymoma.

\section{Study Limitations}

The present study has significant limitations. First, the retrospective, nonrandomized design with selection of VATS or open thymectomy according to signs of vascular and pericardial invasion introduces an obvious selection bias and limits the ability to compare the 2 groups. Our institutional criteria for patient selection result in a large proportion of patients undergoing VATS, which will further increase the difference in patient numbers between the 2 groups in the future. Second, the sample size in this study was far smaller than usually required to detect a difference between groups. For example, if survival was $94 \%$ in 1 group and $91 \%$ in the other group (hazard ratio $=1.5$ ), with 2-sided alpha set at 0.05 , each group would require 335 patients and 90 events to obtain a power of $90 \%$ for detecting a significant difference between groups. To obtain a power of $80 \%$ for detecting a significant difference under the same conditions, 250 patients would be required in each group. However, it is difficult for a single center to recruit such a large sample size, considering the rarity of thymoma. Third, the follow-up period was insufficient to reach firm conclusions about 10-year outcomes in the entire cohort. Thymoma is a disease that should be followed up for at least 3 decades, ${ }^{24,35}$ and further follow-up of our patients is warranted.

\section{CONCLUSIONS}

The intermediate-term oncologic outcomes after VATS thymectomy for the treatment of early-stage thymoma are as favorable as outcomes after open thymectomy. PTx also seems to be feasible and safe for the treatment of noninvasive thymoma without MG, although there is no known oncologic principle supporting treatment by PTx rather than TTx. Follow-up of our patients will continue to evaluate the long-term outcomes of VATS thymectomy for the treatment of early-stage thymoma.

\section{References}

1. Regnard JF, Magdeleinat P, Dromer C, Dulmet E, De Montpreville V, Levi JF, et al. Prognostic factors and long-term results after thymoma resection: a series of 307 patients. J Thorac Cardiovasc Surg. 1996;112:376-84.

2. Okumura M, Ohta M, Tateyama H, Nakagawa K, Matsumura A, Maeda H, et al. The World Health Organization histologic classification system reflects the oncologic behavior of thymoma: a clinical study of 273 patients. Cancer. 2002;94: 624-32.

3. Nakagawa K, Asamura H, Matsuno Y, Suzuki K, Kondo H, Maeshima A, et al. Thymoma: a clinicopathological study based on the new World Health Organization classification. J Thorac Cardiovasc Surg. 2003;126:1134-40.

4. Wright CD, Wain JC, Wong DR, Donahue DM, Gaissert HA, Grillo HC, et al. Predictors of recurrence in thymic tumors: importance of invasion, World Health Organization histology, and size. J Thorac Cardiovasc Surg. 2005;130:1413-21.

5. Davenport E, Malthaner RA. The role of surgery in the management of thymoma: a systematic review. Ann Thorac Surg. 2008;86:673-84.

6. Yim APC. Video-assisted thoracoscopic management of anterior mediastinal masses. Surg Endosc. 1995;9:1184-8.

7. Chen YJ, Kao EL, Chou SH. Videothoracoscopic resection of stage II thymoma: prospective comparison of the results between thoracoscopy and open methods. Chest. 2005;128:3010-2.

8. Sakamaki Y, Kido T, Yasukawa M. Alternative choices of total and partial thymectomy in video-assisted resection of noninvasive thymomas. Surg Endosc. 2008;22:1272-7.

9. Odaka M, Akiba T, Yabe M, Hiramatsu M, Matsudaira H, Hirano J, et al. Unilateral thoracoscopic subtotal thymectomy for the treatment of stage I and II thymoma. Eur J Cardiothorac Surg. 2010;37:824-6.

10. Takeo S, Tsukamoto S, Kawano D, Katsura M. Outcome of an original videoassisted thoracoscopic extended thymectomy for thymoma. Ann Thorac Surg. 2011;92:2000-6. 
11. Wang LS, Huang HH, Lin TS, Huang BS, Chien KY. Malignant thymoma. Cancer. 1992;70:443-50.

12. Chen J, Weisbrod GL, Herman SJ. Computed tomography and pathologic correlation of thymic lesions. J Thorac Imaging. 1988;3:61-5.

13. Tomiyama N, Muller NL, Ellis SJ, Cleverley JR, Okumura M, Miyoshi S, et al. Invasive and noninvasive thymoma: distinctive CT features. J Comput Assist Tomogr. 2001;25:388-93.

14. Masaoka A, Monden Y, Nakahara K, Tanioka T. Follow-up study of thymomas with special reference to their clinical stages. Cancer. 1981;48:2485-92.

15. Rosai J, Sobin L. Histological typing of tumors of the thymus. In: Rosai J, Sobin L, eds. World Health Organization, International Histological Classification of Tumors. Berlin, New York: Springer; 1999:9-14.

16. Müller-Hermelink HK, Engel P, Kuo TT, Ströbel P, Marx A, Haris NL, et al. Tumors of the thymus: introduction. In: Travis WD, Brambilla E, MüllerHermelink HK, Harris CC, eds. World Health Organization Classification of Tumors. Pathology and Genetics of Tumors of the Lung, Pleura, Thymus and Heart. Lyon, France: International Agency for Research on Cancer (IARC) Press; 2004:148-51.

17. Masaoka A, Monden Y. Comparison of the results of transsternal simple, transcervical simple, and extended thymectomy. Ann N Y Acad Sci. 1981;377:755-65.

18. Shigemura N, Shiono H, Inoue M, Minami M, Ohta M, Okumura M, et al. Inclusion of the transcervical approach in video-assisted thoracoscopic extended thymectomy (VATET) for myasthenia gravis: a prospective trial. Surg Endosc. 2006; 20:1614-8.

19. Kido T, Hazama K, Inoue Y, Tanaka Y, Takao T. Resection of anterior mediastinal masses through an infrasternal approach. Ann Thorac Surg. 1999;67:263-5.

20. Pennathur A, Qureshi I, Schuchert MJ, Dhupar R, Ferson PF, Gooding WE, et al. Comparison of surgical techniques for early-stage thymoma: feasibility of minimally invasive thymectomy and comparison with open resection. J Thorac Cardiovasc Surg. 2011;141:694-701.

21. Chung JW, Kim HR, Kim DK, Chun MS, Kim YH, Park S-I, et al. Long-term results of thoracoscopic thymectomy for thymoma without myasthenia gravis. J Int Med Res. 2012;40:1973-81.

22. Marulli G, Rea F, Melfi F, Schmid TA, Ismail M, Fanucchi O, et al. Robot-aided thoracoscopic thymectomy for early-stage thymoma: a multicenter European study. J Thorac Cardiovasc Surg. 2012;144:1125-32.
23. Regnard JF, Zinzindohoue F, Magdeleinat P, Guibert L, Spaggiari L, Levasseur P Results of re-resection for recurrent thymomas. Ann Thorac Surg. 1997;64:1593-8.

24. Margaritora S, Cesario A, Cusumano G, Meacci E, D’Angelillo R, Bonassi S, et al. Thirty-five-year follow-up analysis of clinical and pathologic outcomes of thymoma surgery. Ann Thorac Surg. 2010;89:245-52.

25. Lucchi M, Davini F, Ricciardi R, Duranti L, Boldrini L, Palmiero G, et al. Management of pleural recurrence after curative resection of thymoma. J Thorac Cardiovasc Surg. 2009; 137:1185-9.

26. Bernatz PE, Harrison EG, Clagett OT. Thymoma: a clinicopathological study. J Thorac Cardiovasc Surg. 1961:42:424-44.

27. Ruffini E, Mancuso M, Oliaro A, Casadio C, Cavallo A, Cianci R, et al. Recurrence of thymoma: analysis of clinicopathological features, treatment and outcome. J Thorac Cardiovasc Surg. 1997;113:55-63.

28. Kondo K, Monden Y. Myasthenia gravis appearing after thymectomy for thymoma. Eur J Cardiothorac Surg. 2005;28:22-5.

29. Nakajima J, Murakawa T, Fukami T, Sano A, Takamoto S, Ohtsu H. Postthymectomy myasthenia gravis: relationship with thymoma and antiacetylcholine receptor antibody. Ann Thorac Surg. 2008;86:941-5.

30. Agasthian T. Can invasive thymoma be resected by video-assisted thoracoscopic surgery? Asian Cardiovasc Thorac Ann. 2011;19:225-7.

31. Uchiyama A, Shimizu S, Murai H, Kuroki S, Okido M, Tanaka M. Infrasterna mediastinoscopic thymectomy in myasthenia gravis: surgical results in 23 patients. Ann Thorac Surg. 2001;72:1902-5.

32. Lee CY, Kim DJ, Lee JG, Park IK, Bae MK, Chung KY. Bilateral video-assisted thoracoscopic thymectomy has a surgical extent similar to that of transsternal extended thymectomy with more favorable early surgical outcomes for myasthenia gravis patients. Surg Endosc. 2011;25:849-54.

33. Monden Y, Nakahara K, Iioka S, Nanjo S, Ohno K, Fujii Y, et al. Recurrence of thymoma: clinicopathological features, therapy, and prognosis. Ann Thorac Surg. 1985;39:165-9.

34. Haniuda M, Morimoto M, Nishimura H, Kobayashi O, Yamenda T, Iida F. Adjuvant radiotherapy after complete resection of thymoma. Ann Thorac Surg. 1992; 54:311-5.

35. Utsumi T, Shiono H, Kadota Y, Matsumura A, Maeda H, Ohta M, et al. Postoperative radiation therapy after complete resection of thymoma has little impact on survival. Cancer. 2009;115:5413-20. 


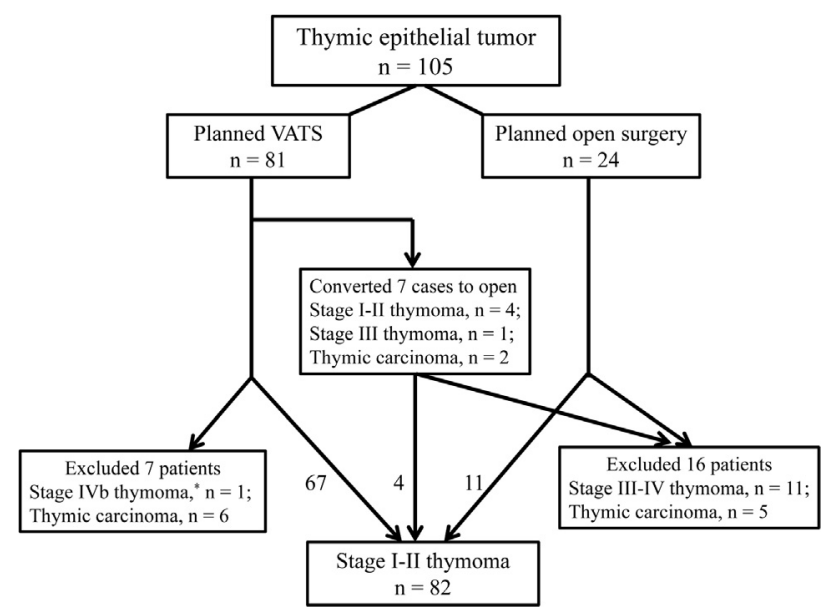

FIGURE E1. Patient selection. *Pulmonary metastasectomy was performed at the time of thymectomy. VATS, Video-assisted thoracoscopic surgery.

TABLE E1. Comparisons of variables between patients who underwent total and partial thymectomy

\begin{tabular}{|c|c|c|c|}
\hline Variable & $\begin{array}{c}\text { Total } \\
\text { thymectomy } \\
(\mathrm{n}=\mathbf{3 6})\end{array}$ & $\begin{array}{c}\text { Partial } \\
\text { thymectomy } \\
(n=46)\end{array}$ & $P$ value \\
\hline Sex & & & $<.01$ \\
\hline Male & $8(22)$ & $24(52)$ & \\
\hline Female & $28(78)$ & $22(48)$ & \\
\hline Age (y) & & & $<.01$ \\
\hline Median & 49.5 & 58.5 & \\
\hline Range & $20-81$ & $28-90$ & \\
\hline Tumor stage & & & .56 \\
\hline Stage I & $18(50)$ & $26(57)$ & \\
\hline Stage II & $18(50)$ & $20(43)$ & \\
\hline WHO histologic type & & & $<.01$ \\
\hline B2-B3 & $14(40)$ & $6(13)$ & \\
\hline Other* & $21(60)$ & $39(87)$ & \\
\hline Tumor size $(\mathrm{cm})$ & & & .11 \\
\hline Median & 3.3 & 4.0 & \\
\hline Range & $1.0-7.0$ & $1.3-15$ & \\
\hline Surgical approach & & & .28 \\
\hline VATS $\dagger$ & $29(81)$ & $42(91)$ & \\
\hline Open & $7(19)$ & $4(9)$ & \\
\hline Combined resection & $4(11)$ & $7(15)$ & .83 \\
\hline Adjuvant radiotherapy & $5(14)$ & $3(6)$ & .46 \\
\hline Follow-up period (mo) & & & .37 \\
\hline Median & 53 & 42 & \\
\hline Range & $2-154$ & $12-147$ & \\
\hline
\end{tabular}

Values are the number (\%) of patients unless otherwise indicated. WHO, World Health Organization; VATS, video-assisted thoracoscopic surgery. *Types A, AB, and B1. †Including 4 cases that were converted to open surgery. 